\title{
Thu Dau Mot University Journal of Science
}

ISSN 2615 - 9635

journal homepage: ejs.tdmu.edu.vn

\section{Species diversity and distribution of wild bees (Hymenoptera: Apoidea) in Binh Chanh District, Ho Chi Minh City}

by Le Van Tho, Dang Van Son (Institute of Tropical Biology, Vietnam Academy of Science and Technology, Vietnam) and Usun Shimizu Kaya, Ryoichi Miyanaga (Shimane University, Japan)

Article Info: $\quad$ Received 18 Jan. 2021, Accepted 1 Mar. 2021, Available online 15 Mar. 2021 Corresponding author:

https://doi.org/10.37550/tdmu.EJS/2021.01.146

\begin{abstract}
As the most significant pollinators of wild plants, bees play an important role in sustaining the natural ecosystems. In this study, we conducted surveys of bee fauna of three different habitat types during dry and rainy seasons of 2020 in Binh Chanh District, Ho Chi Minh City. A total of 169 individuals from 13 bee species belonging to six genera were collected. Of these, eight species are newly recorded from Ho Chi Minh City: Amegilla calceifera, A. himalajensis, A. zonata, Ceratina nigrolateralis, $C$. smaragdula, Xylocopa aestuan, $X$. latipes, Tetragonula fuscobalteata. The species composition of bees was more diverse in forest habitat than rural garden and canalbank habitats. The richness and abundance of bees were significantly higher in the dry season than the rainy season. Apis florea was abundant in forest and rural garden habitats while Ceratina smaragdula occurred plentifully in the canalbank habitat. Eight bee species (Apis cerana, A. dorsata, A. florea, Thyreus himalayensis, Xylocopa latipes, $X$. aestuans, Ceratina smaragdula, and $C$. nigrolateralis) widely distributed throughout all three habitats. By contrast, four bee species (Amegilla calceifera, A. himalajensis, Apis mellifera, and Tetragonula fuscobalteata) exclusively appeared in the forest habitat.
\end{abstract}

Keywords: bee fauna, distribution, species diversity 


\section{Introduction}

Bees are a group of insects belonging to the Apiformes within the superfamily Apoidea of order Hymenoptera. Approcximately 20,000 species of bees are known worldwide. They are the most popular and important insect pollinators of both natural and cultivated vegetation in terrstrial ecosystems (Engel et al., 2020; Michener, 2007). From an economical point of view, honeybees and bumble bees are vey important because they are used commercially for pollination of crops (Ascher et al., 2016). However, unmanaged wild bees are also provided critical services for crop pollination (Soh \& Ngiam, 2013; Ascher \& Pickering, 2020). Recently, some studies have shown that the bee populations are in decline throughout the world. Habitat loss appears to be the major factor for this phenomenon (Michener, 2007; Soh \& Ngiam, 2013). However, the degree of wild bee decline in Vietnam remains unclear, because systematic surveys are lacking in most parts of the country. This report deals with the result of a wild bee survey made in Binh Chanh District, Ho Chi Minh city, in order to obtain some basic information upon the faunal makeup.

\section{Materials and methods}

\subsection{Study area}

The study was conducted in Binh Chanh District in southwest of Ho Chi Minh city, Vietnam. The regional landscape is a mosaic of agricultural fields, villages, forest patches, canals, gardens and urban areas. Bee sampling was done on three different habitat types in the studied area: the forest site (F), canalbank site (C) and rural garden site (G) (Figs 1 and 2). The forest site is located in Le Minh Xuan commune, the garden site in Tan Nhut commune, and the canalbank site in Pham Van Hai commune.

\subsection{Field sampling}

We sampled foraging bees on flowers using aerial nets in March-April (dry season, four times per each habitat) and July-August (rainy season, four times per each habitat) in 2020. Sampling was performed in transect walks during 09:00 to 15:30 on mostly sunny days. Three transects were used for each site. Collectors walked at slower speed and collected bees during $30 \mathrm{~min}$ for each transect (Westphal et al., 2008). In total, 1.5 hours were spent collecting bees at each site at every sampling event. The captures bees were preserved according to the flower species visited.

\subsection{Laboratory analysis}

In the laboratory, the bee specimens were pinned and identified to the finest taxonomic level possible using a Olympus SZ-ST (Olympus, Tokyo, Japan) dissecting microscope and base on the following literatures: Michener (2007), Ascher \& Pickering (2020), Bingham (1897), Engel et al. (2019), Lieftinck (1956, 1962), Vecht (1952), Warrit et al. 
(2012), Lee et al. (2016). The flower plants were identified base on the literatures of Dang et al. $(2011,2013)$.

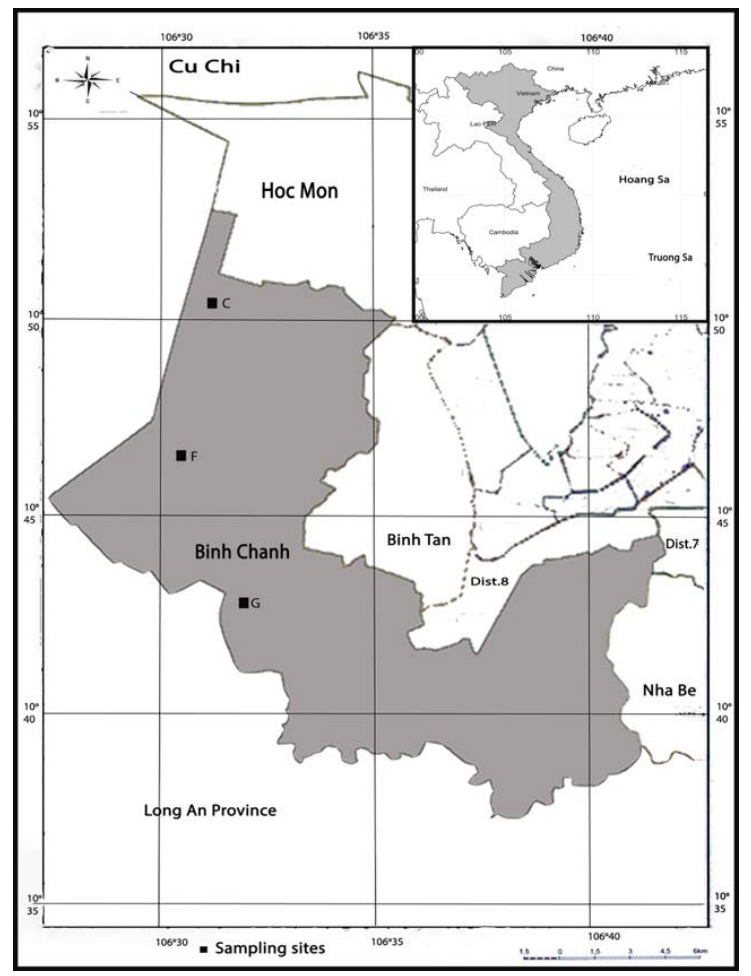

Figure 1. Location of the sampling sites (C: Canalbank site, G: Rural garden site, F: Forest site)
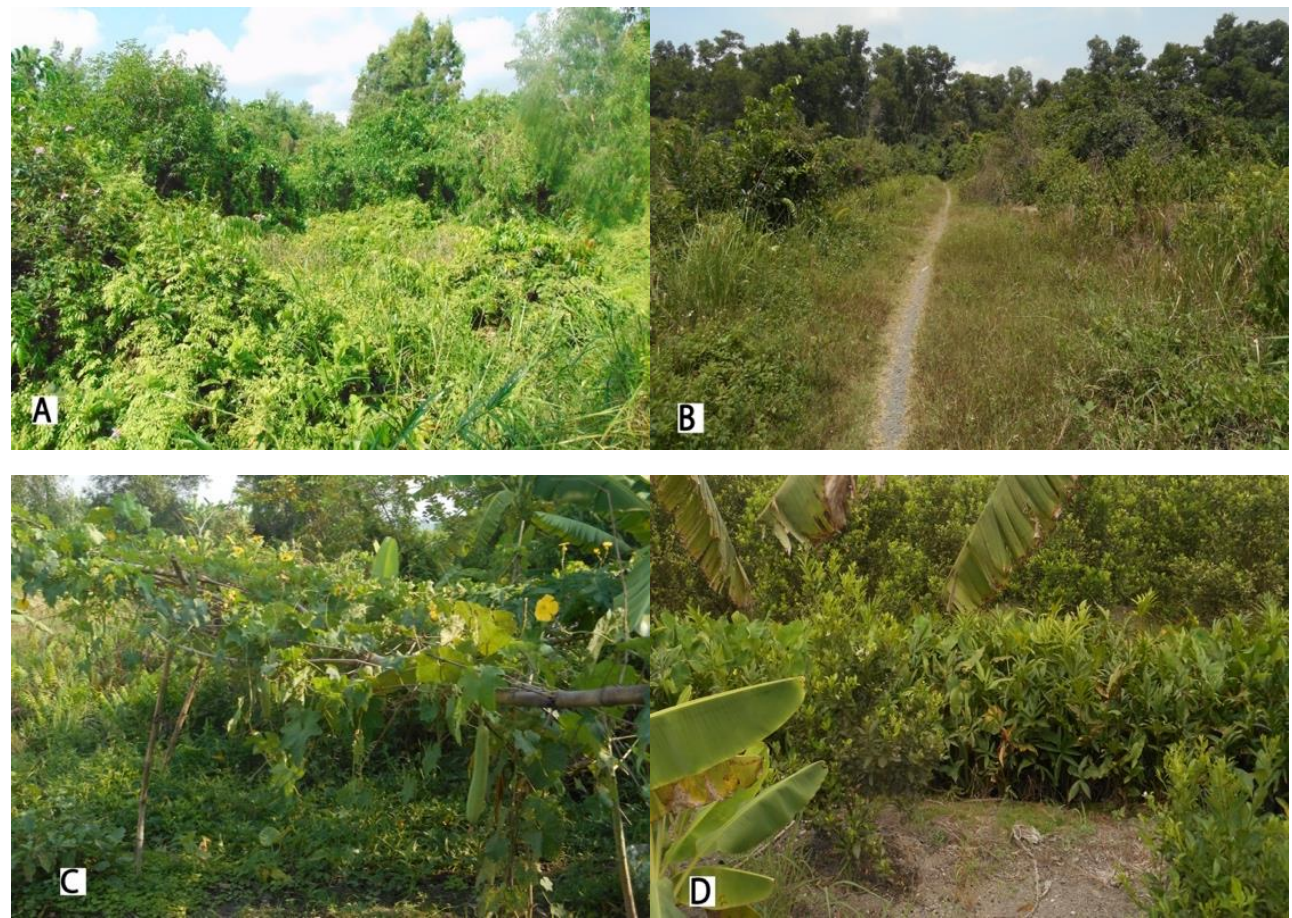


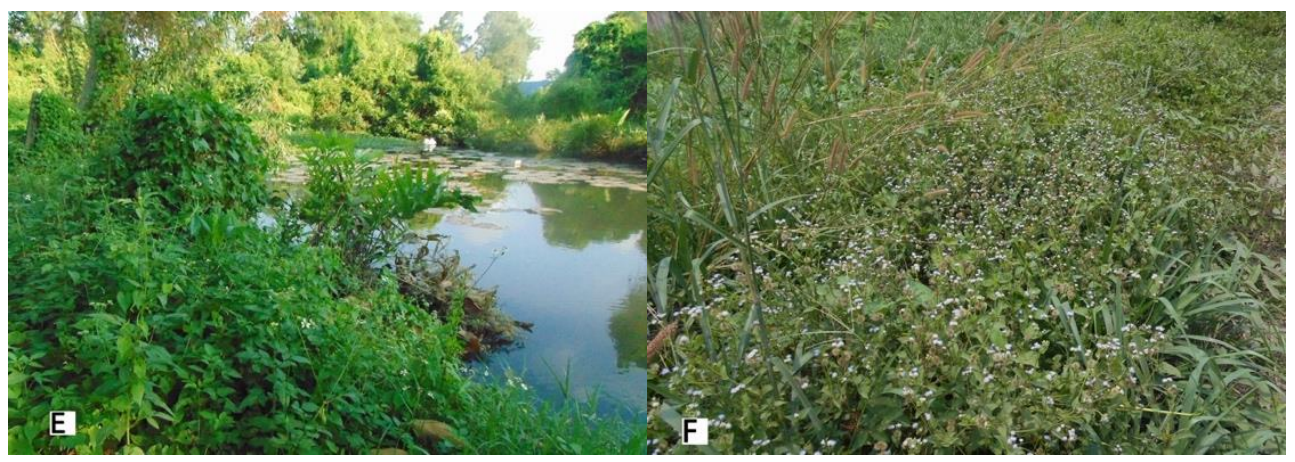

Figure 2. Views of the sampling sites in Binh Chanh District (A, B: Forest site, C, D: Rural garden site, E,F: Canalbank site).

\section{Results and discussions}

\subsection{Species diversity}

In total, 169 individuals belonging to 13 species in seven genera and two families were collected from three habitats (Table 1). Of the 13 species, eight species were new record for Ho Chi Minh city region: Amegilla calceifera, A. himalajensis, A. zonata, Ceratina nigrolateralis, $C$. smaragdula, Tetragonula fuscobalteata, Xylocopa aestuans, and $X$. latipes (Table 1). The rest five species, including four species of genus Apis and one species of genus Thyreus are widely distributed in Vietnam (Le, 2008; Khuat et al., 2012). Three species of them: Apis dorsata, A. florea, and Thyreus himalayensis were previously recorded from Ho Chi Minh city region (Ascher \& Pickering, 2020). Two species of genus Apis, Apis mellifera and A. cerana were kept commercially in traditional and modern beekeepings in Vietnam (Lee, Duwal \& Lee, 2016).

TABLE 1. A list of bee species and their numbers collected on flowers at 3 sampling sites in Binh Chanh District

\begin{tabular}{|c|c|c|c|c|c|c|}
\hline \multicolumn{7}{|c|}{$\begin{array}{l}\text { Phylum ARTHROPODA } \\
\text { Class INSECTA } \\
\text { Order HYMENOPTERA } \\
\text { Family Apidae }\end{array}$} \\
\hline Subfamily & No. & Speices & $\mathbf{F}$ & $\bar{G}$ & $\mathbf{C}$ & Total \\
\hline \multirow{6}{*}{ Apinae } & $1 *$ & Amegilla zonata (Linnaeus, 1758) & 6 & 1 & & 7 \\
\hline & $2^{*}$ & Amegilla calceifera (Cockerell, 1911) & 1 & & & 1 \\
\hline & $3^{*}$ & Amegilla himalajensis (Radoszkowski, 1882) & 1 & & & $\mathbf{1}$ \\
\hline & 4 & Apis cerana Fabricius, 1793 & 8 & 7 & 3 & 18 \\
\hline & 5 & Apis mellifera Linnaeus, 1758 & 1 & & & 1 \\
\hline & 6 & Apis dorsata Fabricius, 1793 & 7 & 3 & 3 & 13 \\
\hline
\end{tabular}




\begin{tabular}{|cclcccc|}
\hline & 7 & Apis florea Fabricius, 1787 & 21 & 13 & 9 & $\mathbf{4 3}$ \\
& $8^{*}$ & Tetragonula fuscobalteata (Cameron, 1908) & 12 & & & $\mathbf{1 2}$ \\
9 & Thyreus himalayensis (Radoszkowski, 1893) & 7 & 1 & 1 & $\mathbf{9}$ \\
\hline & $10^{*}$ & Ceratina nigrolateralis Cockerell, 1916 & 7 & 2 & 1 & $\mathbf{1 0}$ \\
Xylocopinae & $11^{*}$ & Ceratina smaragdula Fabricius, 1787 & 5 & 4 & 13 & $\mathbf{2 2}$ \\
& $12^{*}$ & Xylocopa aestuans Linnaeus, 1758 & 11 & 8 & 4 & $\mathbf{2 3}$ \\
& $13^{*}$ & Xylocopa latipes (Drury, 1773) & 3 & 4 & 2 & $\mathbf{9}$ \\
\hline Total number of species & $\mathbf{1 3}$ & $\mathbf{9}$ & $\mathbf{8}$ & $\mathbf{1 3}$ \\
\hline Total number of individuals & $\mathbf{9 0}$ & $\mathbf{4 3}$ & $\mathbf{3 6}$ & $\mathbf{1 6 9}$ \\
\hline
\end{tabular}

Notes: F: Forest site, G: Rural garden site, C: Canalbank site; * newly recorded species for Ho Chi Minh city.
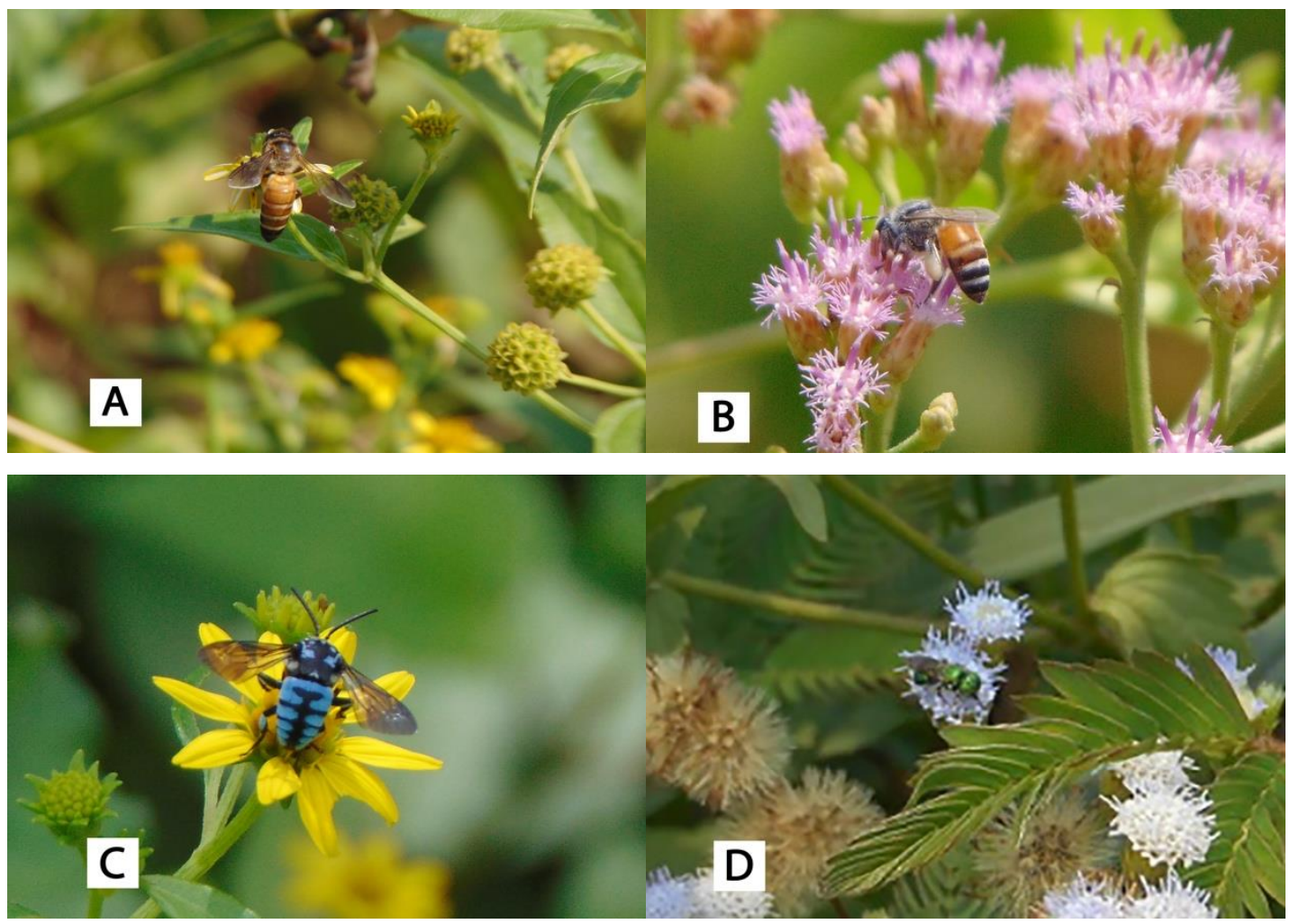


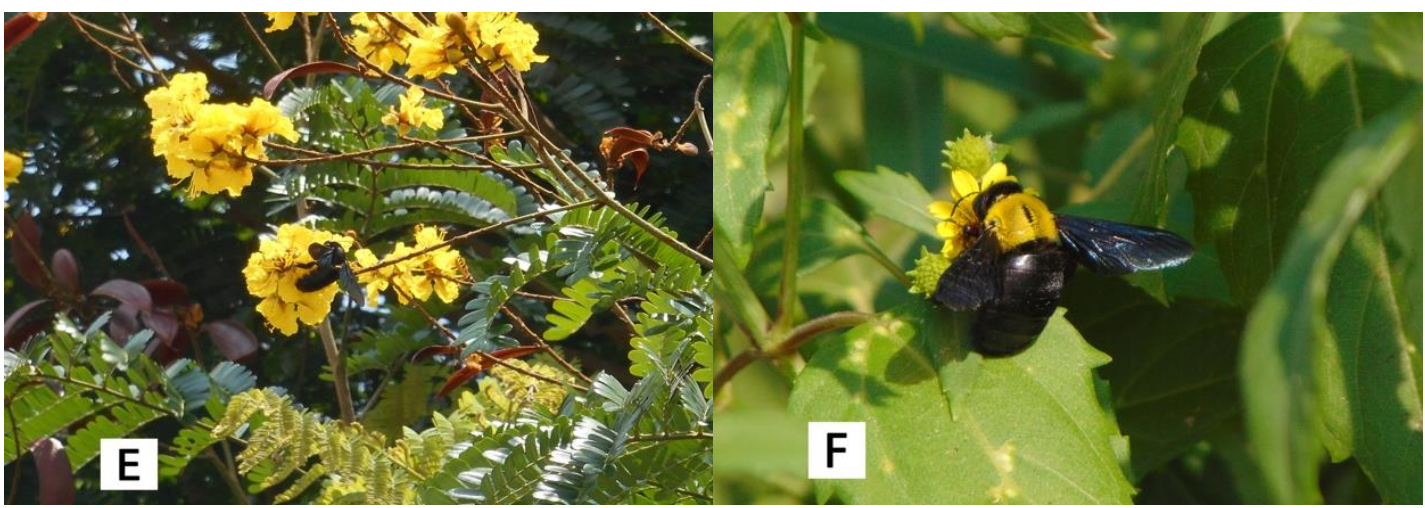

Figure 3. Bees that visit vairous flowers at sampling sites (A: Apis dorsata, B: Apis florea, C: Thyreus himalayensis, D: Ceratina smaragdula, E: Xylocopa latipes, F: Xylocopa aestuans).

Figure 4 shows the relative abundance of 10 species, of which more than 2 individual of each species were collected, in all 3 habitats, with the upper and lower fiducial limits ( $p$ $=0.95$ ), arranged in the descending order of abundance. The most abundant species collected was Apis florea, followed by Xylocopa aestuans, Ceratina smaragdula, A. cerana, A. dorsata, and Tetragonula fuscobalteata. In 3 predominant species, Apis florea, Xylocopa aestuans and Ceratina smaragdula, the lower fiducial limits exceed the value $100 \mathrm{x}$ reciprocal of the total number of sampled species $(100 \times 1 / 13)$ and their cumulative percentage ratio reaches 52.01, that is, involving over half of total individuals collected from 3 sites. 


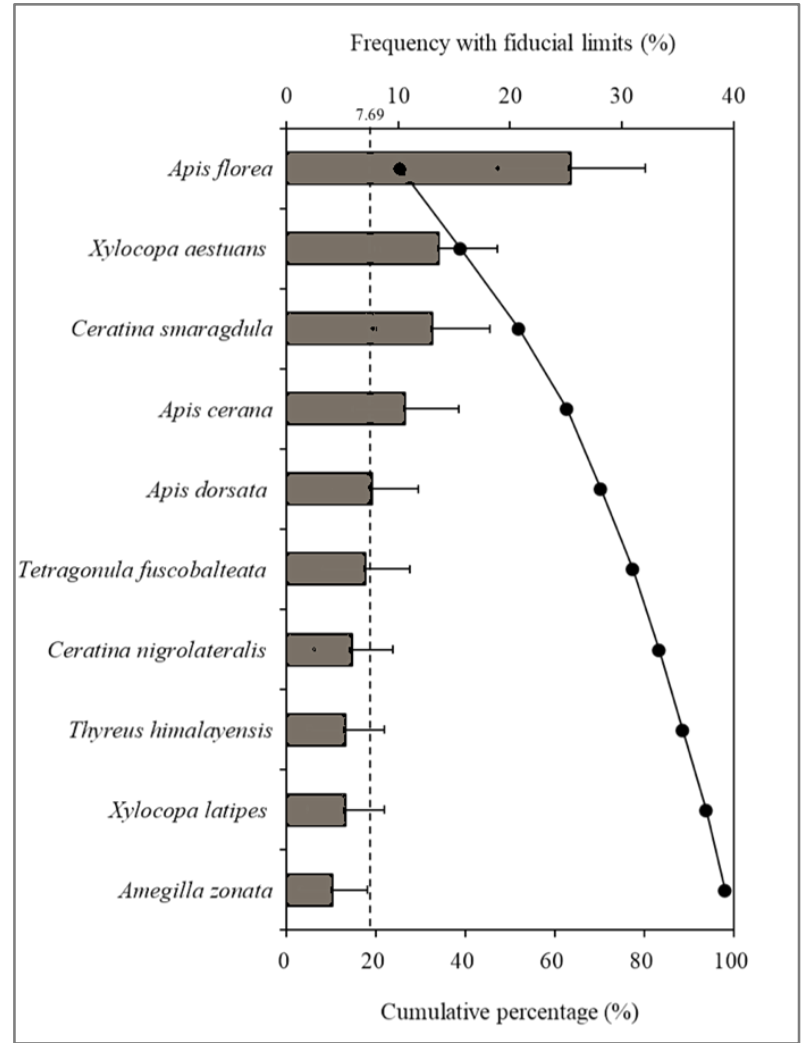

Figure. 4. Relative abundance of 10 predominant species shown by occurrence probability method. Percentage ratios (scale above) of each species is given by a horizontal bar with fiducial limits. Dashed line at left hand is the reciprocal of the number of species sampled multiplied by 100 . Curve line shows cumulative percentage (scale bottom).

Of the 13 species, 3 were represented by a single individual only from the forest site, whereas 8 were common to all 3 sites. Species richness and abundance of bees were highest in the forest site (13 species, 90 individuals), followed by the rural garden site ( 9 species, 43 individuals), and the canalbank site ( 8 species, 36 individuals). Apis florea was the most abundant species in both the forest and rural garden sites, while it was Ceratina smaragdula in the canalbank site. The small stingless bee, Tetragonula fuscobalteata was the subdominant in the forest site, but not collected in other sites. In three sites, species richness and abundance were higher in the dry season (ranged from 7-13 species and 20-62 individuals) than in the rainy season (ranged from 5-7 species and 16-28 individuals) (Fig. 5).
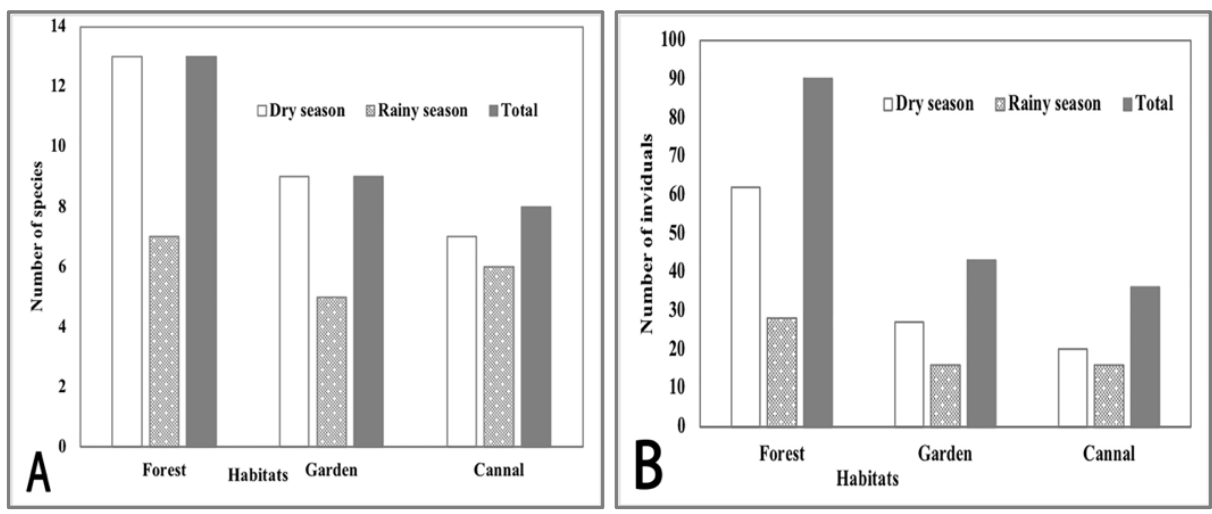
Figure 5. Number of species (A) and individuals (B) of bees sampled in dry and rainy season at three sampling sites in Binh Chanh District

\subsection{Floral resources}

Plants belonging to family Fabaceae, Asteraceae largely distributed in three sampling sites. Convolvulaceae, Myrtaceae, Melastomataceae occurred in forest and canalbank sites. While Cucurbitaceae, Solanaceae, Bignoniaceae, Portulacaceae were recorded in rural garden site. Flowering plants, such as Luffa cylindrica (Cucurbitaceae), Peltophorum pterocarpum (Fabaceae), Melaleuca cajuputi (Myrtaceae), Melastoma malabathricum (Melastomataceae) were frequently visited by large carpenter bees of genus Xylocopa. Meanwhile, small carpenter bees of genus Ceratina commonly visited to flowers of Solanum album (Solanaceae), Ageratum conyzoides (Asteraceae), Ipomoea indica (Convolvulaceae). Other flowering plants: Tecoma stans (Bignoniaceae), Portulaca grandiflora (Portulacaceae), Mimosa pudica (Fabaceae), Sphagneticola trilobata, Bidens pilosa, Pluchea indica (Asteraceae) were visited by other species, such as Apis florea, A. dorsata, A. melifera, A. cerana, and Tetragonula fuscobalteata. Thyreus himalayensis was found on flowers of Sphagneticola trilobata (Asteraceae), and species of genus Amegilla was mainly collected on flowers of Ipomoea maxima (Convolvulaceae) in the survey areas (Fig. 6).
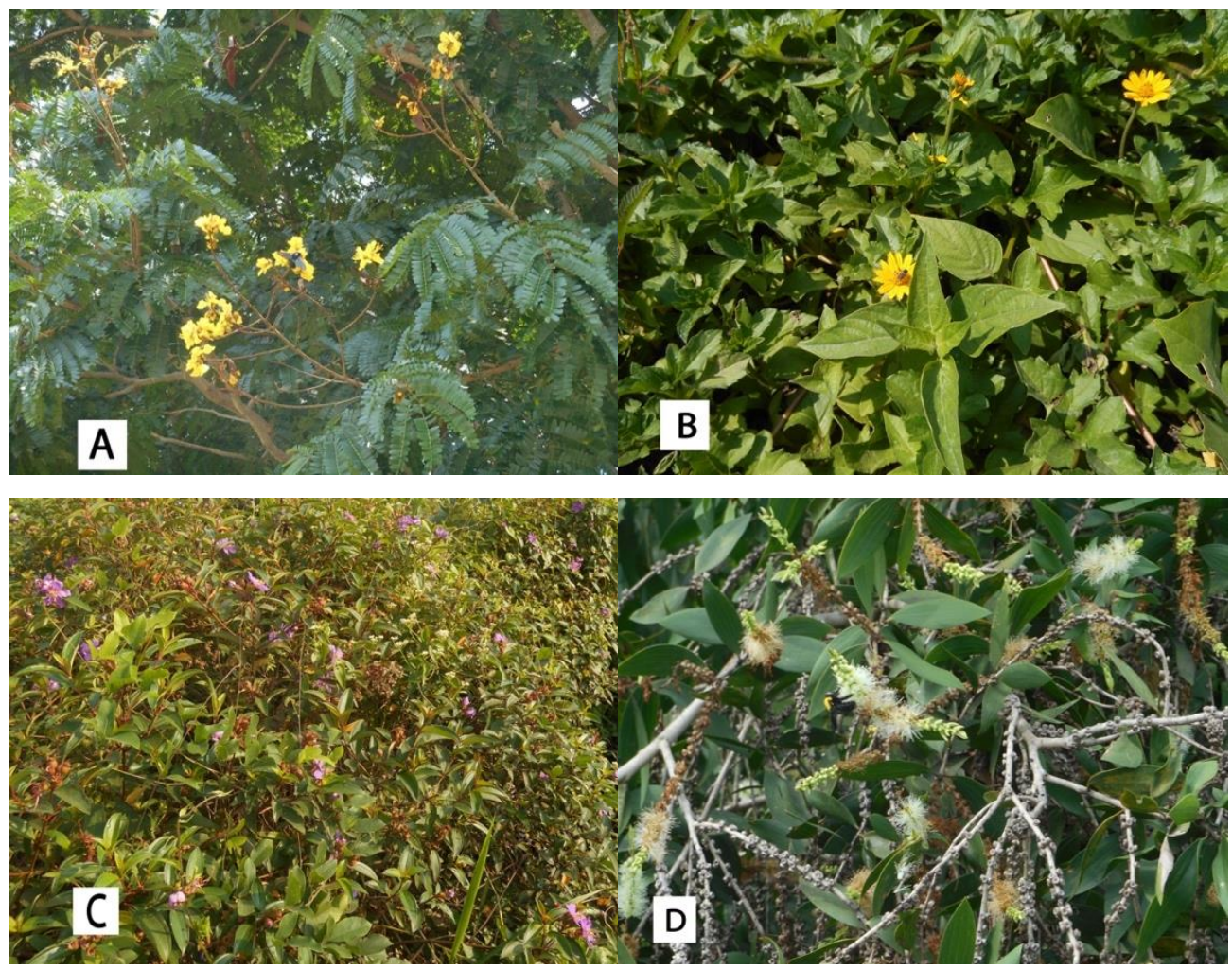

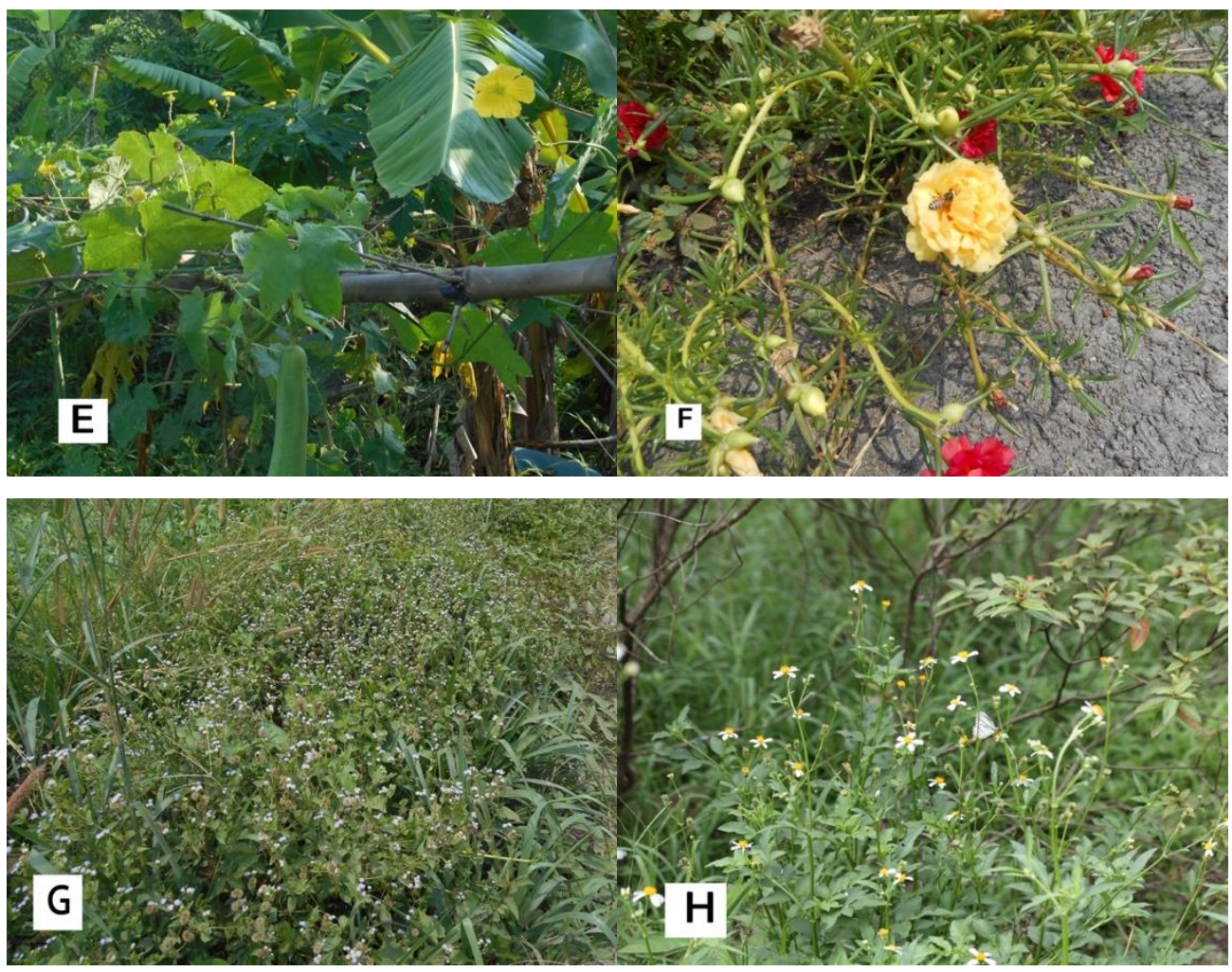

Figure 6. Floral species from which bees were collected (A: Peltophorum pterocarpum; B: Sphagneticola trilobata; C: Melastoma malabathricum; D: Melaleuca cajuputi; E: Luffa cylindrica; F: Portulaca grandiflora; G: Ageratum conyzoides; H: Bidens pilosa).

\section{Conclusions}

Wild bees fauna of Binh Chanh district, suburban west of Ho Chi Minh city was surveyed in 2020, by periodical sampling on flowers at three different habitat types.

The total sample consisting of 13 species and 169 individuals shows the predominance of the genus Apis, followed by Ceratina and Xylocopa in individual number. In species number, Apis was abundant, followed by Amegilla. Eight species: Amegilla calceifera, A. himalajensis, A. zonata, Ceratina nigrolateralis, C. smaragdula, Tetragonula fuscobalteata, Xylocopa aestuan, and X. latipes are collected for the first time in Ho Chi Minh city region. Species richness and abundace of bees were highest in the forest site, followed by the rural garden site, and the canalbank site. Flowering plants which widely occurred in Binh Chanh were families Fabaceae, and Asteraceae. They were extensively distributed in three habitats.

\section{Acknowledgment}

This work was supported by JSPS KAKENHI Grant Number $17 \mathrm{H} 04644$. 


\section{References}

C. Westphal, R. Bommarco, G. Carré, E. Lamborn, N. Morison, T. Petanidou, S.G. Potts, S.P.M. Roberts, H. Szentgyorgyi, T. Tscheulin, B.E. Vaissiere, M. Woyciechowski, J.C. Biesmeijer, W.E. Kunin, J. Settele, I.S. Dewenter (2008). Measuring bee diversity in different European habitats and biogeographical regions. Ecological monographs, 78(4), pp.653-671.

C.D. Michener (2007). The Bees of the World. Johns Hopkins University Press, pp.587632.

D.L. Khuat, X.H. Le, T.H. Dang, H.P. Pham (2012). A preliminary study on bees (Hymenoptera: Apoidea: Apiformes) from northern and north central Vietnam. Jounal of Biology, 34(4), pp.419-426.

H.T. Pham, V.T. Tran (2018). Beekeeping in Vietnam. Asian Beekeeping in the 21st Century, pp.247-267.

J. Vecht (1952). A preliminary revision of the Oriental species of the genus Ceratina (Hymenoptera, Apidae). Zoologische Verhandelingen, pp.1-85.

J.S. Ascher, J. Pickering, (2020). Discover Life bee species guide and world checklist (Hymenoptera: Apoidea: Anthophila), http://www.discoverlife.org/mp/20q? guide=Apoidea_species.

J.S. Ascher, P.H. Heang, S. Kheam, K. Ly, S. Lorn, S.X. Chui, S.D. Greef, G. Chartier, S. Phauk (2016). A report on the bees (Hymenoptera: Apoidea: Anthophila) of Cambodia. Cambodian Journal of Natural History, (1), pp.23-29.

M.A. Lieftinck (1956). Revision of some oriental anthophorine bees of the genus Amegilla Firese (Hymenoptera, Apoidea). Zoologische Verhandelingen, 30, pp.141.

M.A. Lieftinck (1962). Revision of the Indo-Australian species of the genus Thyreus Panzer (= Crocisa Jurine) (Hym., Apoidea, Anthophoridae) Part 3. Oriental and Australian species. Zoologische Verhandelingen, 53, pp.1-212.

M.S Engel, C. Rasmussen, V.H. Gonzalez (2020). Bees, Phylogeny and Classification. Encyclopedia of Social Insects, pp.1-17.

M.S. Engel, S. Kahono, D. Peggie (2019). A key to the genera and subgenera of stingless bees in Indonesia (Hymenoptera: Apidae). Treubia, 45, pp.65-84.

N. Warrit, C.D. Michener, C. Lekprayoon (2012). A review of small carpenter bees of the genus Ceratina, subgenus Ceratinidia, of Thailand (Hymenoptera, Apidae). Proceedings of the Entomological Society of Washington, 114(3), pp.398-416.

S. Lee, R.K. Duwal, W. Lee (2016). Diversity of stingless bees (Hymenoptera, Apidae, Meliponini) from Cambodia and Laos. Journal of Asia-Pacific Entomology, 19(4), pp.947-961.

T.C. Bingham (1897). The Fauna of British India including Ceylon and Burma. Taylor and Francis, London-Berlin, 1, pp.414-559. 
V.S. Dang (2013). The handbook of useful plants from $\mathrm{Cu}$ Chi in Ho Chi Minh City. Agriculture publishing house, pp.1-220.

V.S. Dang, H. Tran (2011). The status of plant resources in Binh Chanh district, Ho Chi Minh City. Proceedings of the $4^{\text {th }}$ National Scientific Conference on Ecology and Biological Resources, pp.1281-1285.

X.H. Le (2008). Diversity of bee superfamily (Hym.: Apoidea) from Vietnam. Proceedings of the $7^{\text {th }}$ Vietnam National Conference on Entomology, pp.934 -938.

Z.W.W. Soh, R.W.J. Ngiam (2013). Flower-visiting bees and wasps in Singapore parks (Insecta: Hymenoptera). Nature in Singapore, 6, pp.153-172. 